\title{
Polymer concrete
}

\author{
Abstract \\ in:
a. Crackup
b. Being alkaline
c. Permeability (against soluble salt, water and etc.)
d. Steel corrosion in concrete
e. Low resistance against warm and cold degrees
f. Low tension

Improvement in Civil Engineering and developing industries, is due to instant need for constructing materials whit new and efficient executive proportions. Polymer concrete is new combination which is first constructed in United States since 1950. One of the most important reasons for developing polymer concrete could be known the Portland concrete weakness. Most important weak points in Portland concrete can be divided

There are many ways to correct these weaknesses; such as using sheets (to correct No 3 and 5) and cathode protection (for No 4) and... that each one of them can correct just one weakness. In some places in which concrete is infested by most pre-mentioned weaknesses (like bridge bases), it causes too many damages that none of these ways can be a good solution in long time (of project or exploitation). In additional to improve concrete mechanical properties, polymer concrete cause vast increase abrasion resistance, resistance to soluble acid, alkali and chemical soluble and also tolerance against warm and cold degrees. These concrete also noticeably decrease among of materials. One of the most important reasons that causes large improvement in concrete mechanical properties rather than regular concrete can be found in these concretes break mechanism and in regular concrete, matrix break is because of losing hydrated cement bonds; but in these kind of concretes, because of strong covalent bond, most of the time, the break occurs in aggregate. For this reason, strong Quartz aggregate, Basalt and Granite are used in polymer concrete. Other important and searchable polymer concrete feature is its crawl and servicing degree which requires real cognition of its behavior and also this concrete optimization. Polymer concrete is a combination of materials in which aggregates are attached by a polymer glue in a condensed place. Polymer concrete contains no hydrated cement. Though, Portland cement can be used in polymer concrete as aggregates or filler. Polymer concrete properties mostly depend on the amount of polymer that is used and its properties. Aggregates and filler materials also have effect on polymer concrete properties.

Keywords: polymer concrete, aggregates, concrete mechanical, basalt and granite
Volume 2 Issue 5 - 2018

\author{
Kaveh Ostad-Ali-Askari,' Vijay P Singh,' \\ Nicolas R Dalezios, ${ }^{3}$ Theodore C Crusberg ${ }^{4}$ \\ 'Department of Civil Engineering, Isfahan (Khorasgan) Branch, \\ Islamic Azad University, Isfahan, Iran \\ ${ }^{2}$ Department of Biological and Agricultural Engineering \& \\ Zachry Department of Civil Engineering, Texas $A$ and $M$ \\ University, USA \\ ${ }^{3}$ Laboratory of Hydrology, Department of Civil Engineering, \\ University of Thessaly, Greece \& Department of Natural \\ Resources Development and Agricultural Engineering, \\ Agricultural University of Athens, Greece \\ ${ }^{4}$ Department of Biology and Biotechnology, Worcester \\ Polytechnic Institute, USA
}

Correspondence: Kaveh Ostad-Ali-Askari, Department of Civil Engineering, Isfahan (Khorasgan) Branch, Islamic Azad University, Isfahan, Iran, Email koa.askare@khuisf.ac.ir

Received: May 25, 2018 | Published: October 26, 2018

\section{Introduction}

\section{Polymer}

Polymer is a very huge molecule created by attaching many small molecules called monomer. With size change, molecule features change too. With changing the molecule length, the product feature change. With changing the size and mass of the molecule, compounds deposition to firm solid state.

Polymer structure: Polymer can be divided to tow general structure; thermoplastic and thermoset. The basic difference is in the intermolecular relation. The energy of polymer chain Splicer in thermoplastic polymer, is secondary intermolecular forces (such as Vendorous bond). This kind of polymers usually melt in suitable soluble and solvent molecules distinguish polymer chain and form solution. Losing solvent will return this kind of polymers to the first place. Polymer chains show chemical reaction in thermoset polymer and primitive chemical bonds will be formed among them that called cross link; so that general polymer structure is like three dimensional networks and spatial. Connective power in cross link looks like as monomer in polymer chains; so after forming cross link, this kind of polymer can be considered as a huge three dimensional molecular. This polymer has a good stability against solutions. Cross link existence limits polymer chains movements and this polymer significantly refrain its solid state.

Polymer properties: Polymers properties depend on their molecular mass and chemical structure. Polymer properties dependence on molecular mass for a hypothetical polymer is shown in Figure $1 .^{1}$ Being cross links in polymer chains improves polymer mechanical properties. In thermoplastic polymer with no cross link, polymer chains slip on one another because of power or heat and Vendorous forces between them disappear. After movement, intermolecular forces appear again. Thermoplastic polymer returns to its first state weakly. This happening is shown in Figure $2 .{ }^{2}$ Cross link in thermoset polymer restrict polymer chain relative movement and it can be considered that under power shape shift in this polymer is like a three dimensional network under power shape shift. Polymer chains move a little from each other by electric charge or heat in thermoset polymer; but cross link won't be distinguished (unless at the last charge). Heat causes displacement in a part of chain or in a chain in thermoplastic polymer and it makes chains split on each other and polymer loses 
its solid state. Cross links restrain polymer chains from too much move in thermoset polymer. So it would be expected that thermoset polymer mechanical properties reduce because of heat; but since cross links doesn't distinguish, these mechanical properties doesn't lose completely. Heat effect on polymer mechanical properties is shown in Figure 3 symbolically. ${ }^{3}$

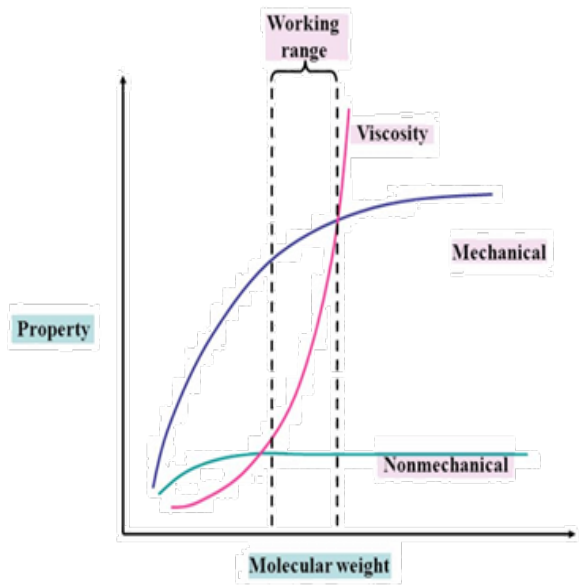

Figure I Polymer properties dependence on molecular mass for a hypothetical polymer.

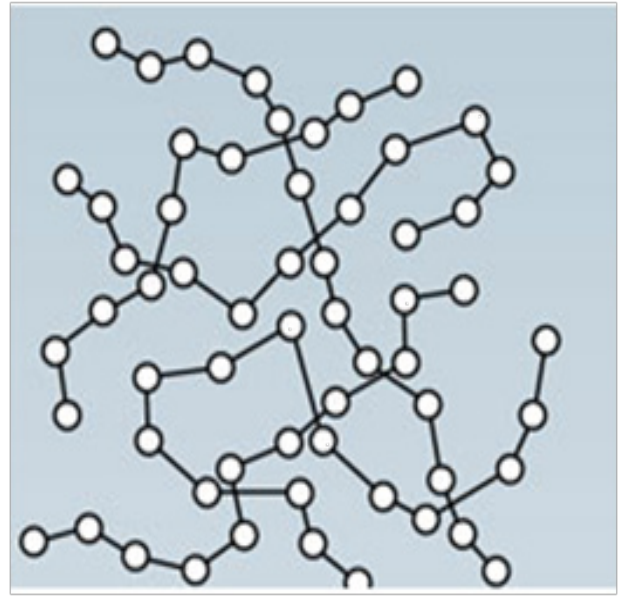

Figure 2 Thermoplastic polymer.

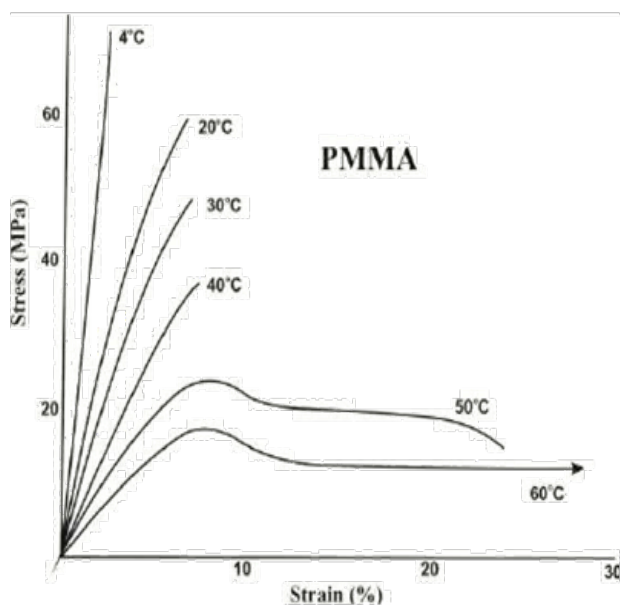

Figure 3 Heat effect on polymer mechanical properties.

\section{Polymer concrete component}

As it's said, polymer concrete is formed by two main principles, aggregates and polymer glue.

Aggregate: Aggregates in polymer concrete most have highest quality. Aggregates of silica, quartz, granite, high quality limestone, and other aggregates with good quality are suitable to be used in polymer concrete. Consumed aggregates most be dry or a little bit damp; anyway, its surface has to be completely dry; unless used polymer glue has ability to stick on wet surfaces. Humidity, dust, or any other pollution on aggregates surface reduce aggregates and polymer glue tenacity. Hugest used aggregates size, alike polymer cement concrete, depends on component size, reinforcement density and thickness of under repair area. Biggest aggregates shouldn't be bigger than onethird depth of under repair area. Aggregates grading should be chosen in a way that dry mashed aggregates fill the least empty space. This saves needed polymer glue to attach all the aggregates and economic. ${ }^{4}$

Polymer splicer: According to polymer concrete, any polymer splicer can be used as polymer glue in polymer concrete. But according to what feature expected from polymer concrete, usually thermoset are used as polymer splicer. To make cross links in polymers or resins, a reaction initiator is used that be added to the resin during use. Polymer concrete is created by different resins and monomers, such as epoxy, polyester, acrylic and methyl methacrylate. These polymers usually have good resistance against water and chemical materials; but their chemical resistance reduces by warming. The remarkable features of these polymers are discussed below.

Epoxy: Epoxies are usually contained of one resin, one hardener, reaction retardants and sometimes of inorganic fillers and Thixotropic. Epoxies are the most common splicer which are used in polymer concrete. The features of epoxy can be categorized as below:

a. Due to low shrinking during cook and because of their surface and molecular tension that increase their tenacity to different grounds, they usually have good tenacity to most of the materials.

b. Epoxies have good resistance in alkali area of concrete.

c. Epoxies can be formed in the way that cook in $-18 \mathrm{C}$ or have operation time and enough performance in $38 \mathrm{C}$.

d. Some epoxies stick to wet and dampened surfaces and some even work under water.

e. Epoxies have good resistance in large usage range.

f. Epoxies have good chemical resistance.

Polyester: Polyester features are:

A. Relatively shrinking during operation.

B. Polyesters don't have good stickiness to wet and humid surfaces. Although recent researches show that Vinyl ester, a kind of polyester, can be used on wet surfaces.

C. Some polyesters have low resistance against the alkali and soluble,

D. Polyesters are usually flammable at $38 \mathrm{C}$. The primer (hardener) that used for polyesters disintegrate quickly over $32 \mathrm{C}$ and might cause fire or explosion. That's why polyesters should not be stored for a long time. In the other word, polyesters have short time of usage rather than epoxies. ${ }^{5}$

Acrylics: Acrylics (Methyl methacrylate) features are so much alike polyesters.

Polymer concrete and portland cement concrete features comparison 
As it's said before, polymer concrete features depend so much on the amount of used polymer. In compressive, flexural \& tensile strength and linear thermal expansion coefficient, polymer concrete is higher than Portland cement concrete; while polymer concrete elasticity modulus is smaller than Portland cement concrete. This features are discussed below.

\section{Mechanical strength}

Polymer concretes mostly have higher compressive, flexural \& tensile strength rather than Portland cement concrete. Also polymer concrete cohesive bond to concrete and steel surfaces is better than regular concrete.

In Portland cement concrete, aggregates splicer is cement pulp and aggregates little participles. In addition to being discrepancy and non-isotropic, this splicer has very weaker tensile strength than its compressive strength. This low tensile strength is why concrete break under load, usually begins by creating and extending crack(due to This low tensile strength) in this splicer. ${ }^{6}$ On the other hand, Portland cement concrete strength depends on the place of pulp bond and aggregates in addition to cement splicer resistance. Except concretes with Pozzolan, in other regular concretes, transition area is usually a weak area on break mode and depends on concrete resistance.

Polymer concrete mechanical strength:

I. Being more homogenous and isotopic and also high splicer tensile strength.

II. Polymer well stickiness to aggregates and eliminate transition area more than Portland cement concrete.

\section{Elongation}

Concrete is fragile and its break is sudden, at the time of break, it has no elongation. Because of limited polymer chains movement from each other (this movement is limited by cross links), polymer concrete shows shapeable attitude after load. ${ }^{7}$

\section{Elasticity modulus}

Elasticity modulus of polymer concrete is generally lower than Portland cement concrete, because polymer elasticity modulus is generally lower than aggregates, so polymer concrete elasticity modulus depends so much on polymer elasticity modulus; but because of reducing the difference between aggregate elasticity modulus and splicer (cement pulp) and also because of transition area in Portland cement concrete, elasticity modulus depends on both aggregate and cement pulp.

\section{Linear thermal expansion coefficient}

Linear thermal expansion coefficient of polymer concrete, is almost two times of Portland cement concrete. Linear thermal expansion coefficient of polymer concrete which depends on polymer and aggregate linear thermal expansion, reduces by aggregate proportion to polymer glue increase (Figure 4).

\section{Penetrance}

Polymer concrete penetrance is lower than Portland cement concrete because of polymer splicer waterproof area and polymer dense structure. ${ }^{8}$

\section{Chemical resistance}

Chemical resistance of polymer concrete is higher than Portland cement concrete because of high polymer chemical resistance and polymer splicer dense structure and penetrance reduction.

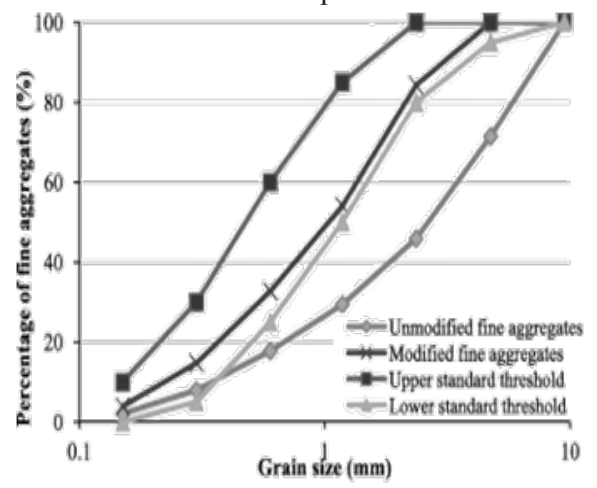

(a)

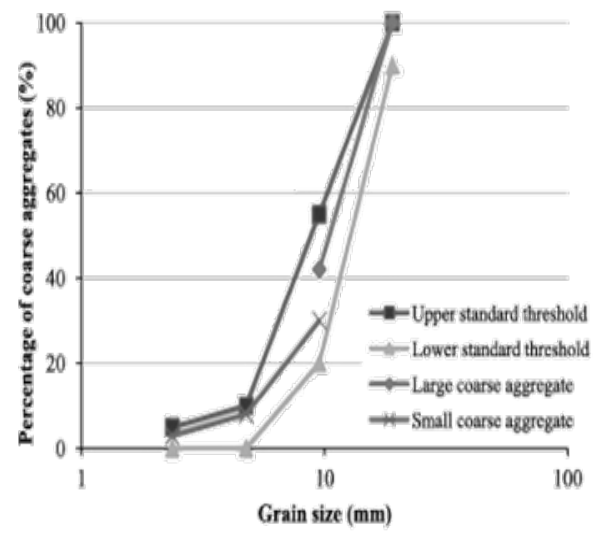

(b)

Figure $\mathbf{4}$ aggregate proportion to polymer glue.

\section{Strength obtain}

Polymer concrete strength obtain and curing process is much longer than Portland cement concrete. This concrete usually gains its ultimate mechanical strength in first few hours.

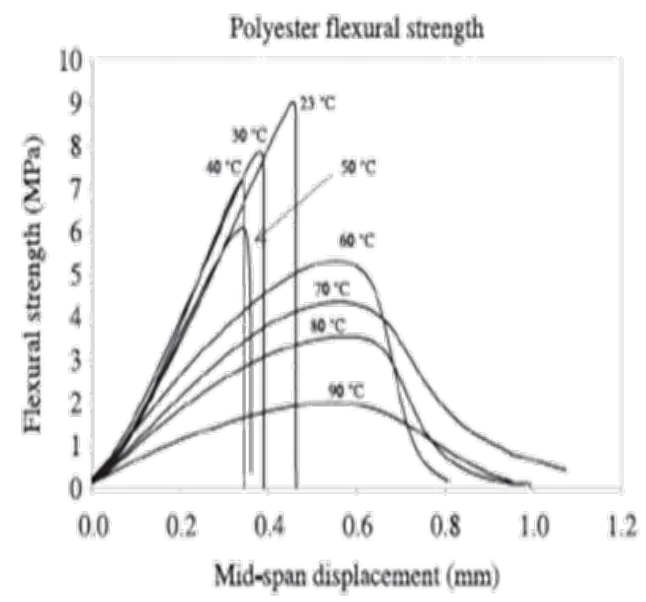

Figure $\mathbf{5}$ Temperature effect on mechanical properties in one kind of polymer concrete.

Temperature effect on polymer concrete
characteristics

Rise in temperature reduces polymer concrete characteristics. 
This matter is because that polymer features depend on temperature (Figure 3). Temperature effect on mechanical properties in one kind of polymer concrete is shown in Figure 5.

\section{Polymer and portland cement concrete compound system function}

Because of difference between Linear thermal expansion coefficient and elasticity modulus in polymer and Portland cement concrete, these two compound system function must be studied more carefully.

\section{Thermal performance}

Consider simple model shown in Figure 6 in which a polymer concrete layer (b) is placed on Portland cement concrete (a). Since polymer concrete linear thermal expansion coefficient is bigger than Portland cement concrete, rise in temperature increases length more Figure 6 and vice versa; fall in temperature decreases length more Figure 6. this matter causes Shear stresses in Intersection of two concretes and it's up to concretes strength and temperature conditions during performance, it can cause Intersection detachment, underneath concrete destruction or polymer concrete break. This matter specially, in areas with high temperature variation effect, is very important. After visit from Shahid Abbaspour dam weir (Karun Dam. 1) in winter of 1380 by concrete association experts, polygonal breaks had been seen in epoxy mortar which is used for repairing the weir surface. In researches, it was found that cracks are because of temperature variation during repairs and operation temperature. In other words, repairs are done in drought season (summer) when the level of water is low and its $40 \mathrm{C}$; but in winter it comes to less than 10 $\mathrm{C}$ degree. So during operation, the temperature of underneath concrete and epoxy mortar is up; but in cold season, epoxy mortar contracts more than underneath concrete because of its higher Linear thermal expansion coefficient, so it breaks as result. Operating polymer concrete in colder seasons or using polymer-treated cement mortar is the fundamental solution. ${ }^{9}$

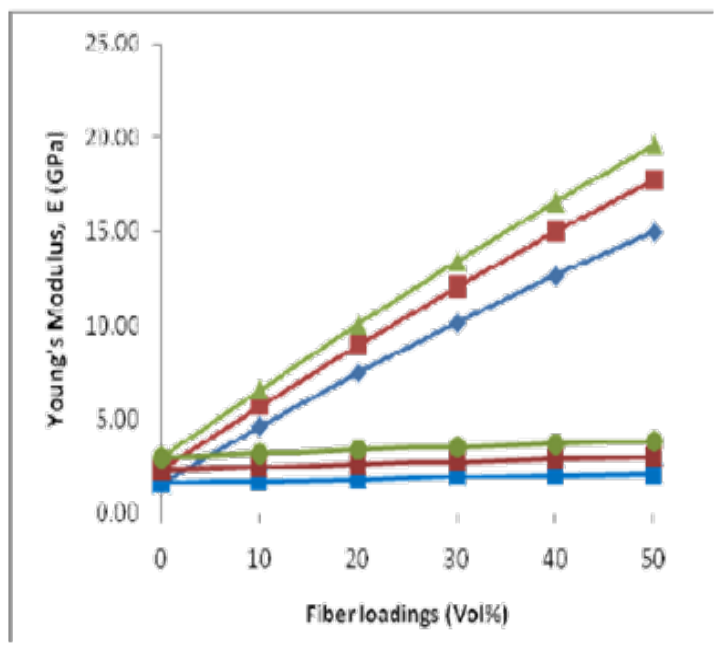

Figure 6 Elasticity modulus.

\section{Under load function}

Under same load, material with less elasticity modulus (polymer concrete) transforms more than material with higher modulus. If both material have different elasticity modulus when external load (compressive or tensional) enters parallel to tenacity surface, most part of the load carried by material with higher modulus and it has more tension. This matter is up to both material tenacity resistance or with higher modulus, can ends up to Intersection separation or break in harder material. When external load enters perpendicular to Intersection, and if it is compressive, stiffness difference would cause separation in Intersection. On the other hand, material with higher elasticity modulus places condition on lateral contraction for the material with lower modulus, and it makes big tensions in material with lower modulus near Intersection which can end up to Intersection separation. Elasticity modulus inconsistency effect on both situations is shown in Figure 6. ${ }^{10,11}$

\section{Polymer modified concrete}

Polymer modified concrete can be divided in two groups:

a. Injectable concretes

b. Polymer-cement concrete

\section{Injectable concretes}

By injecting a monomer with low viscosity (in gas or liquid form) into a concrete, hardened precast Portland cement is created that these interjected monomers become into solid polymer under physical effects (Ultraviolet light radiation or heat) or chemical effects (Catalysts). Polymer injectable concrete is produced from regular concrete in the way that first air exits from an open pore (by vacuum suction or alternative monomers and pressure); then the pore will be filled by spreading a monomer with low viscosity or by a monomer polymer combination and monomer intromission or Polymer Clay -monomer combination will be Polymerized that this process is done in economic and ordinary ways (radiation, heat, chemical). The major disadvantage of these materials is that a big part of pores is filled by polymers which have formed a reinforcement connected net. This concrete structure might be injected in various (deep) layers or only in one external layer that it depends on the resistance or strength it needs. The most important reason for not using these products is their high price; as the monomer which used in them, is expensive and production process is more complicated than unmodified concrete. Result of concrete injecting was significant improvement in tensile, compressive and impact strength, endurance reinforcement and permeability reduction against water and blue salt solutions such as Sulfates and Chlorides. Compressive strength can be increased from $35 \mathrm{Mpa}$ to $140 \mathrm{Mpa}$. Iron absorption reduces too. Also, resistance against ice-melt phenomenon (reflux) increases remarkably. It is noted that we can reach to more resistance by injecting steam into concrete (autoclaved) that in these cases, a compressive strength ratio to density is almost 3 times more than steel. Although Elastic Modulus is normally bigger than polymer autoclaved injectable concretes, the maximum strain is higher in break.

Those monomers which are used widely in concrete injection, are vinyl kind; such as Methyl methacrylate (M.M.A), Styrene, Acrylonitrile, and T-butyl Styrene vinyl acetate. Acrylic monomer systems such as Methacrylate with its combinations with Acrylonitrile are preferred for injection; because they have low viscosity, suitable moisture features, high reactivity, and good price; so they would be products with better characteristics and more efficiency. After using injection of bio functional monomers and multi-functional monomers (cross-link additive), to addition (M.M.A), a cross link net is created and as result, mechanical, Thermal and chemical resistance increases a lot. Of course, products improvement is up to cross-link Temperature. One cross-link additive is usually used one vinyl monomer such as (M.M.A). Monomers of Thermoset polymer is used to produce polymer injectable concretes by increasing thermal resistance very 
much (resistance against frazzle by heat). These are also included of epoxy polymer clay and Polyester, unsaturated styrene. These monomers and polymer clays are partly viscosity; so using them cause injection reduction. Of course viscosity can be reduced by combining them with low viscosity monomer like (M.M.A). Injectable concrete is used in depth of buildings and construction works including structural ceilings, structures with top performance, sewer pipes, sea water storage tanks, Desalination and distilled water installation, marine Structures, wall prefab panels, tunnel seaming, prefab sections of tunnel and pool. Injectable concretes are partially used to protect bridges and concrete structures against frazzle and deterioration. It is also used to repair building structures frazzle such as Dropped ceiling panels and underground garages floor and staircase floor.

\section{Polymer cement concrete}

A concrete is modified when a part (10-15 percent) of its splicer cement weight is replaced by artificial polymer. This product is included off one monomer, Polymer Clay, monomer with a polymer ooze in a cement concrete. Monomer and Polymer Clay-monomer polymerization is done by adding a catalyst to the composite. This technology is much like regular concrete. Therefore, polymer-cement concrete can be added to required usage immediately. It should be mentioned that polymer injectable concrete is usually used as prefab structures. The feature of polymer-cement concrete produced by modified concrete with various polymers, changes from weak to absolute suitable. Weak products features are related to most polymers and monomers incompatibility to a part of concrete. Better features are made by using Polymer Clays such as unsaturated cross link Polyester with styrene or epoxy. To reach more real and basic modification from Unmodified concrete, a very huge proportion of polymers is needed that this modification and improvement is not explainable by Increasing the price. The result concrete modification in polymer way (suspending Colloidal polymer particles in water) is great improvement in features under a logical cost. That's why there is many (latex) ways now to use in polymer-cement concrete products and mortars. Most of regular latex ways are based on Poly (methyl methacrylate) which is called acrylic latex. For instance, Polyvinyl acetate, Vinyl chloride, Copolymer, Nitrile plastics, regular plastics and each of polymer products has its own specific physical characteristic. For example, Acrylate essence provides a good connected waterproof between modified polymer and concrete components; while the result of using styrene essence is a high compressive strength. Operating polymercement concrete essence differs from regular concrete, because polymer forms a thin membrane on products surface, a part of internal moisture is stored, which will be used for cement hydration and because of this formed thin membrane, operating these products with water is mostly fewer than regular concrete. Polymer-cement concrete created from polymer essence usually shows a great connection to steel bars and used concretes. Good plasticity, resistance against water penetrating and blue salt solutions and resistance against ice-melt phenomenon, is their other properties. Their Flexural strength and resistance (toughness) is usually more than unmodified concretes too. Their elasticity model can be more (not necessary); because it depends on used polymer essence. Generally, because their creep is often more than regular, it can be reduced by one of these polymer essences: Poly acrylic, Styrene, Butadiene, Copolymer, Polyvinylidene chloride.

Shrinkage by drying polymer-cement concrete is mostly less than regular concrete too. Shrinkage average is up to water to cement ratio, amount of cement, amount of polymer and operating conditions. Their sensitivity in high temperatures is more than regular concretes as well. For instance, creep increases in higher temperature than regular cement concrete; while flexural strength, flexural modulus and elasticity modulus decreases. These effects are more and bigger in things made from elastomeric (Styrene-Butadiene) essence rather than things made from Thermoplastic polymers (Acrylic). For example, polymer-cement concrete which is made by Thermoplastic essences, only hold half of its flexural strength and elasticity modulus in $45 \mathrm{C}$ temperature.

Polymer-cement concrete with essences major usage is included of: Ceilings surface, because they are without dust and relatively inexpensive. Due to low shrinkage, it has good resistance against penetration of various liquids such as water and salt solutions and has good connection to old concrete, specially, for thin bedding $(25 \mathrm{~mm})$ on bridges concrete floors, Stainless topping, concrete repairs and patching.

\section{Polymer concrete usage}

Polymer concrete is used in:

1) Repair cases

2) Bridges topping

3) Industrial bedding and concrete protective covers

4) Prefab parts

Polymer concrete can be used as a repairing material with quick operating features and high primary and ultimate resistance to repair concrete structures. At first, most of these concretes were designed to repair highways surfaces-which have light traffic; but slowly their usage expanded in other concrete structures. One of the most important polymer concrete advantages is structure repair which is because of their well tenacity to underneath concrete-their feasibility to conduct in thin layers on concrete surface. Polymer repair materials are provided in the form of binary pulp (primer) or pre-packed ternary mortar. When polymer concrete is used as bridges topping and industrial bedding, creates a protective layer on concrete surface because of low penetrance and high chemical resistance, which prevents from corrosion. Using polymer concrete to produce prefabrication parts is limited to façade members and industrial parts now. One of the important advantages of producing prefab parts by polymer concrete, is it's without the need of operating system. Thought AC1548.6R bylaw has offered ways to use polymer concrete structure, but its usage for producing prefab sections is narrow right now because of its high price and extreme changes of features after changing the temperature.

\section{Conclusion}

a. Properties of polymer concrete are mostly better than cement based concrete.

b. Mechanical, physical and chemical characteristics of polymer concrete depend on temperature and by rising temperature, reduces. Therefore, during using polymer concrete, production temperature most be considered and the kind of concrete be determined based on that.

c. Due to more linear thermal expansion coefficient in polymer concrete rather than cement based concrete, performing temperature most be considered. Fettling concrete surface in warm season with polymer concrete can ends up to detachment and impairment in cold season.

d. Because of fewer elasticity modulus in polymer concrete than cement based concrete and its extreme mechanical strength reduction in heat weather, it should be used very carefully for structural purposes. 
e. Since quick cook and operating, polymer concrete has wide usage in highways surfaces repair and bridges topping.

f. Polymer concrete tenacity to beneath surface is too much; but it should be noted that some specifics stick to wet surfaces and beneath surface commonly should be dry during their operation.

g. Polymer concrete is mostly offered in pre packed form and that's why their most features have been appointed before. Unlike cement based concrete which consumer can choose, modify or change features during work and up to conditions, there are very limited options in this concrete.

\section{Acknowledgements}

None.

\section{Conflict of interest}

The authors declare that there is no conflict of interest.

\section{References}

1. Jong Wha Bai. Seismic Retrofit for Reinforced Concrete Building Structures. Consequence-Based Engineering (CEB) Institute Final Report: Texas University. 2003:1-30.

2. Jianhua Liu. Rehabilitation of Seismically Deficient Reinforced Concrete Structures-State of the art. University of Alberta: An Interdisciplinary Journal. 2006

3. Jack P Moehle. State of Research on Seismic Retrofit of Concrete Building Structures in the US. US-Japan Symposium and Workshop on Seismic Retrofit of Concrete Structures-State of Research and Practice.
$2000 ; 1-16$

4. Giorgio Monti. Seismic Upgrade of Reinforced Concrete Columns with $F R P$. University Spienza Roma. Italy.

5. Michael N Fardis. Seismic Assessment and Retrofitting of Existing Buildings According to Eurocode 8. Fifth National Conference on Earthquake Engineering. 2003;1-10.

6. Tetsuo Yamkawa, Mehdi Banazadeh, Shogo Fujikawa. Emergency Retrofit of Damaged RC Columns Right after Seismic Attack Using PreTensioned Aramid Fiber Belts. 1st Conference on Application of FRP Composite in Construction and Rehabilitation of Structures. 2004.

7. Ghassan K Al Chaar, Georgy E Lamb. Design of Fiber-Reinforced Polymer Materials for Seismic Rehabilitation of Infilled Concrete Structures. US Army Corps of Engineering-Research and Development Center. 2002;1-84.

8. Mazzolani FM, Della Corte G, Faggiano B. Full Scale Testing and Analysis of Innovative Techniques for Seismic Upgrading of RC Buildings. 2006.

9. Ali Sehat Tabatabaei. Energy Dissipation systems for seismic resistance. Iran civil center.

10. Yamakawa T, Nasrollahzadeh Nesheli K, Satoh H. Seismic Retrofitting of RC Columns Using Restressed Aramid Fiber Belts. Fourth International Conference of Earthquake Engineering and Seismology. 2003;1.

11. Sadoughi M, Yarandi, Saatcioglu M. Seismic Retrofit of Rectangular Concrete Column with Splice Deficiencies by External Restressing. Fourth International Conference of Earthquake Engineering and Seismology. 2003. 